\section{To Speak for the Trees}

Diana Beresford-Kroeger. 2019. ISBN 0-978-073527-5072 Penguin Random House Canada. CA \$32.00 + shipping. Contact: cpokorchak@penguinrandomhouse.com

anadian botanist, biochemist and visionary Diana Beresford-Kroeger's startling insights into the hidden life of trees have already sparked a quiet revolution in how we understand our relationship to forests. Now, in a captivating account of how her life led her to these illuminating and crucial ideas, she shows us how forests can not only heal us but save the planet.

When Diana Beresford-Kroegerwhose father was a member of the Anglo-Irish aristocracy and whose mother was an O'Donoghue, one of the stronghold families who carried on the ancient Celtic traditions-was orphaned as a child, she could have been sent to the Magdalene Laundries. Instead, the O'Donoghue elders, most of them scholars and freehold farmers in the Lisheens valley in County Cork, took her under their wing. Diana became the last ward under the Brehon Law. Over the course of three summers, she was taught the ways of the Celtic triad of mind, body and soul. This included the philosophy of healing, the laws of the trees, Brehon wisdom and the Ogham alphabet, all of it rooted in a vision of nature that saw trees and forests as fundamental to human survival and spirituality. Already a precociously gifted scholar, Diana found that her grounding in the ancient ways led her to fresh scientific concepts. Out of that huge and holistic vision have come the observations that put her at the forefront of her field: the discovery of mother trees at the heart of a forest; the fact that trees are a living library, have a chemical language and communicate in a quantum world; the major idea that trees heal living creatures through the aerosols they release and that they carry a great wealth of natural antibiotics and other healing substances; and, perhaps most significantly, that planting trees can actively regulate the atmosphere and the oceans, and even stabilize our climate.

This book is not only the story of a remarkable scientist and her ideas, it harvests all of her powerful knowledge about why trees matter, and why trees are a viable, achievable solution to climate change. Diana eloquently shows us that if we can understand the intricate ways in which the health and nected to the global forest, and strengthen those connections, we will still have time to mend the self-destructive ways that are leading to drastic fires, droughts and floods.

Diana Beresford-Kroeger is a worldrecognized botanist, medical biochemist and author, whose work uniquely combines western scientific knowledge and the traditional concepts of the ancient world. Her books include The Sweetness of a Simple Life, The Global Forest, Arboretum Borealis, Arboretum America-which won the National Arbor Day Foundation award welfare of every living creature is con-

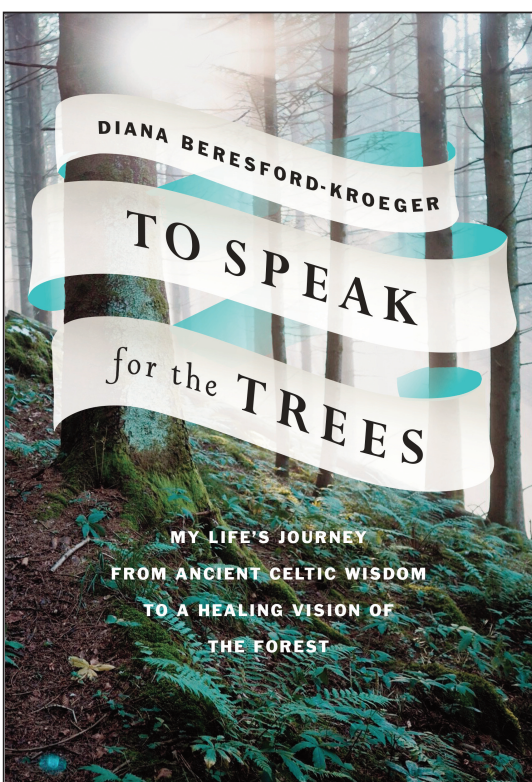

for exemplary educational work on trees and forests-Time Will Tell, and A Garden for Life. Among many honours, Beresford-Kroeger was inducted as a WINGS WorldQuest Fellow in 2010 and elected as a Fellow of the Royal Canadian Geographical Society in 2011. More recently, in 2016, the Society named her one of 25 women explorers of Canada. Her work has inspired artists and writers, as well as leading scientists. She is the author and presenter of a feature documentary, Call of the Forest, and is also at the heart of an upcoming three-part series airing on PBS called The Truth about Trees. Currently she is advocating on behalf of an ambitious global "bioplan" encouraging ordinary people to develop a new relationship with nature and join together to restore the global forest. 